\title{
Protection for the great Indian bustard
}

\section{Asad Rahmani}

In 1981, as a result of Dr Sálim Ali's assessment of the deteriorating status of the great Indian bustard, the Bombay Natural History Society embarked on a five-year project to study the ecology and distribution of the bird. The author, who has worked on the great Indian bustard in three places in India and who took part in the BNHS bustard project, describes its findings.

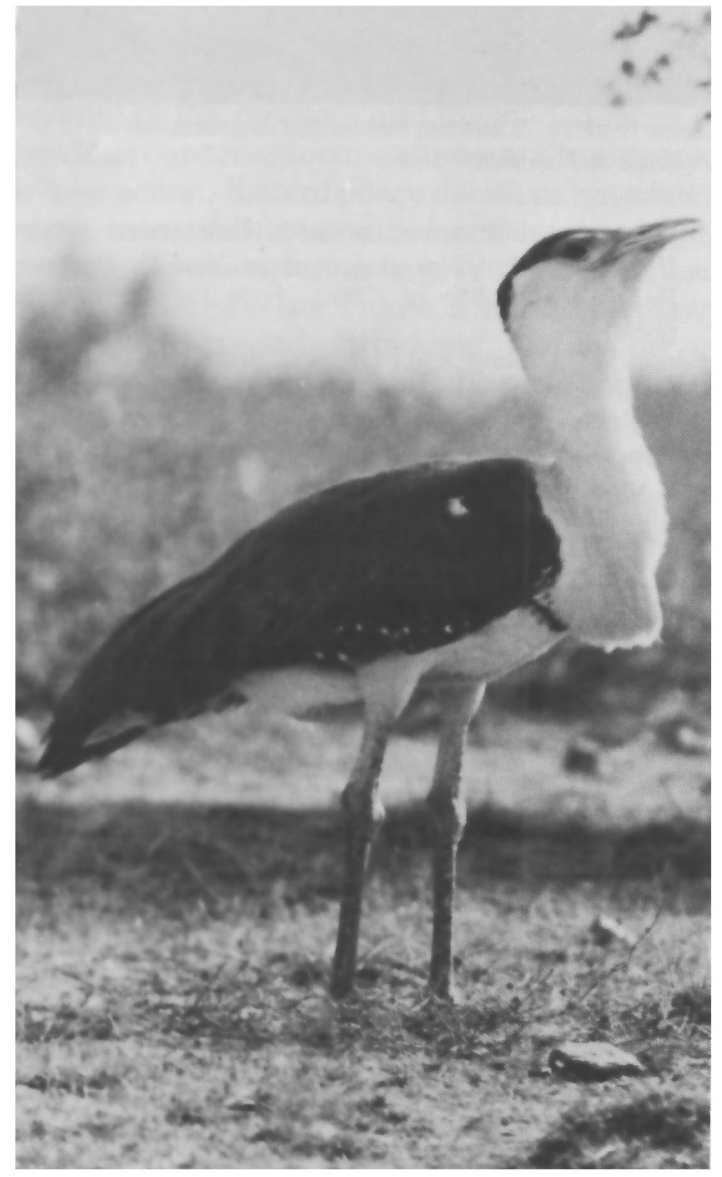

A male great Indian bustard (Asad Rahmani) Bombay Natural History Society)
The great Indian bustard Ardeotis nigriceps was formerly widely distributed in grassland, savanna and open scrub over most of the country. Over the last 100 years, indiscriminate shooting and destruction of its habitat by expansion of agriculture and overgrazing by livestock have made it one of India's rarest birds and it is now endangered.

The bustard has been legally protected since 1952 , but its numbers continued to fall because implementation of the law was difficult. In 1969 Sálim Ali estimated that around 1000 bustards survived in the whole country and, during the XIth Technical Meeting of the IUCN in 1969 in New Delhi, he recommended strict conservation measures (Ali, 1970). However, the Government took no concrete steps and the population continued to decline. In December 1978, the bustard was thrown into the limelight when Arab falconers entered India and gave rise to fears that these birds might become their victims. For 15 days, until the falconers were forced to leave the country, the bustard was on the front pages of all leading Indian newspapers.

Spurred on by this active support, the newly formed Tourism and Wildlife Society of Indian organized an International Seminar on Bustards in 1980 at Jaipur, India, where delegate after delegate pleaded the cause of the great Indian bustard. All available information about the GIB (an acronym made popular during the Seminar) was published in a book Bustards in Decline, 
edited by Paul D. Goriup and Harsh Vardhan (1983). The Seminar demonstrated that information on the present distribution of the GIB was either lacking or inadequate, and that its ecology and behaviour were not fully known, a hindrance in taking effective conservation measures. As the premier research and conservation body in India, the Bombay Natural History Society (BNHS) assumed the responsibility of studying this rare and elusive bird. In 1981 it started a five-year project under the guidance of Dr Sálim Ali to study its ecology and distribution, and to suggest measures for its conservation and rehabilitation.

\section{Surveys}

The BNHS field surveys revealed that the species survives in six Indian states (Figure 1), with
Rajasthan holding more than half of the population. One of the most encouraging findings was that the status of the bird is not as desperate as had been believed. For example, the 1980 estimate was 15 bustards for Andhra Pradesh although 'no survey had been done' (Goriup and Vardhan, 1983). During one of our surveys in 1984 we saw 35 birds in one locality in that State. In subsequent surveys we found bustards in two more places, and four further areas were identified where bustards are definitely present. Therefore, the total bustard population of the State should not be less than 80-100 birds. Similarly, 50-100 birds are present in each of the states of Maharashtra and Madhya Pradesh. However, the bustard population of Gujarat state in western India has suffered a massive decline, and it is feared that if urgent conservation

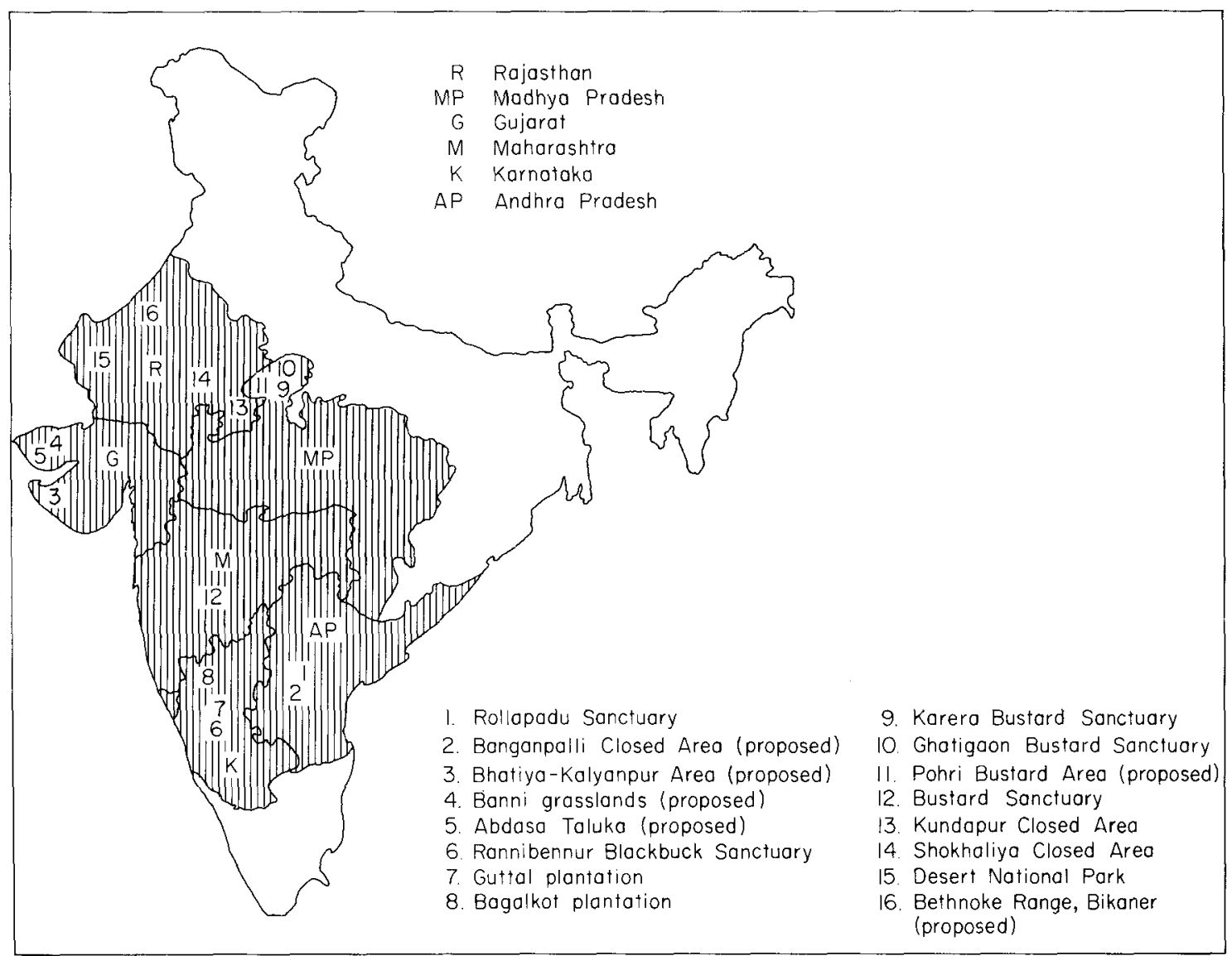

Figure 1. The Indian States in which the great Indian bustard still survives. 
measures are not taken now, the species will disappear for ever from there. Three extensive surveys were undertaken between 1982 and 1985 , during which only six birds could be found in two widely separated areas, although we found evidence of bustards in three more places. Recommendations for the establishment of three sanctuaries were given to the Government in 1985; these were accepted, but a severe drought prevented work being started. It is hoped that these sanctuaries will be established in the near future.

Rajasthan State holds 500-1000 great Indian bustards. Being a 'State bird', it benefits from great popularity and its population is increasing in most places. During a survey in 1983 we found 52 birds, but in a survey of almost the same areas in 1986 we found 104. The birds are present in nine districts, but we could visit only five. A large population survives in the Thar desert and some good bustard areas are approachable only on camel back. Added to this, the bird's nomadic behaviour makes sighting it at any particular place unpredictable. Therefore, we probably saw only 10-20 per cent of the population. More detailed surveys are planned for accurate assessment of the bustard population of Rajasthan.
After preliminary surveys in $1981-82$, intensive work on the bustard was started by establishing two field stations in two different areas, Karera in Madhya Pradesh and Nanaj in Maharashtra, almost $1000 \mathrm{~km}$ apart.

\section{Population trends}

Although the species is still not secure, the trend of the population is encouraging. There are 16 bustard sanctuaries/closed areas where numbers are increasing (Table 1). For example, in the Karera Bustard Sanctuary in Madhya Pradesh the population increased from 14 adult birds to 25-30 between 1982 and 1986. Similarly, in the Nanaj area in Maharashtra, strict protection resulted in 22 birds being recorded in 1983, while in 1981 only eight birds had been seen. In some of the well-protected parts of the 3162-sqkm Desert National Park in Rajasthan 10-15 bustards can be seen easily in a morning.

\section{Biology}

In the non-breeding season, the great Indian bustard lives in small groups of five to ten birds, with males and females in their own subgroups; mixed flocks are rare (Rahmani and Manakadan,

Table 1. Existing and proposed great Indian bustard sanctuaries

\begin{tabular}{|c|c|c|c|c|}
\hline State & & Name & $\begin{array}{l}\text { Approximate no. } \\
\text { of bustards }\end{array}$ & Size* \\
\hline Andhra Pradesh & $\begin{array}{l}1 . \\
2 .\end{array}$ & $\begin{array}{l}\text { Rollapadu Sanctuary } \\
\text { Banganpalli Closed Area (proposed) }\end{array}$ & $\begin{array}{l}40-50 \\
10-15\end{array}$ & $\begin{array}{l}400 \text { ha } \\
-\end{array}$ \\
\hline Gujarat & $\begin{array}{l}3 . \\
4 . \\
5 .\end{array}$ & $\begin{array}{l}\text { Bhatiya-Kalyanpur Area (proposed) } \\
\text { Banni grasslands (proposed) } \\
\text { Abdase Taluka (proposed) }\end{array}$ & $\begin{array}{l}5-10 \\
\text { Not known } \\
\text { Not known }\end{array}$ & $\overline{840 \mathrm{sq} \mathrm{km}}$ \\
\hline Karnataka & $\begin{array}{l}6 . \\
7 . \\
8 .\end{array}$ & $\begin{array}{l}\text { Rannibennur Blackbuck Sanctuary } \\
\text { Guttal plantation } \\
\text { Bagalkot plantation }\end{array}$ & $\begin{array}{c}10-15 \\
8-10 \\
3-5\end{array}$ & $\begin{array}{l}123 \mathrm{sq} \mathrm{km} \\
490 \mathrm{ha} \\
-\end{array}$ \\
\hline Madhya Pradesh & $\begin{array}{r}9 . \\
10 . \\
11\end{array}$ & $\begin{array}{l}\text { Karera Bustard Sanctuary } \\
\text { Ghatigaon Bustard Sanctuary } \\
\text { Pohri Bustard Area (proposed) }\end{array}$ & $\begin{array}{l}30-35 \\
10-15 \\
10-12\end{array}$ & $\begin{array}{l}202 \mathrm{sq} \mathrm{km} \\
512 \mathrm{sq} \mathrm{km} \\
-\end{array}$ \\
\hline Maharashtra & 12. & Bustard Sanctuary & $50-60$ & $7818 \mathrm{sq} \mathrm{km}$ \\
\hline Rajasthan & $\begin{array}{l}13 . \\
14 . \\
15 . \\
16 .\end{array}$ & $\begin{array}{l}\text { Kundapur Closed Area } \\
\text { Shokhaliya Closed Area } \\
\text { Desert National Park } \\
\text { Bethnoke Range, Bikaner (proposed) }\end{array}$ & $\begin{array}{c}10-15 \\
80-100 \\
200-400 \\
10-15\end{array}$ & $\begin{array}{l}\text { ca. } 10 \mathrm{sq} \mathrm{km} \\
17 \mathrm{sq} \mathrm{km} \\
3162 \mathrm{sq} \mathrm{km} \\
400 \mathrm{ha}\end{array}$ \\
\hline
\end{tabular}

*The sizes of some of the proposed bustard sanctuaries are still undetermined. 


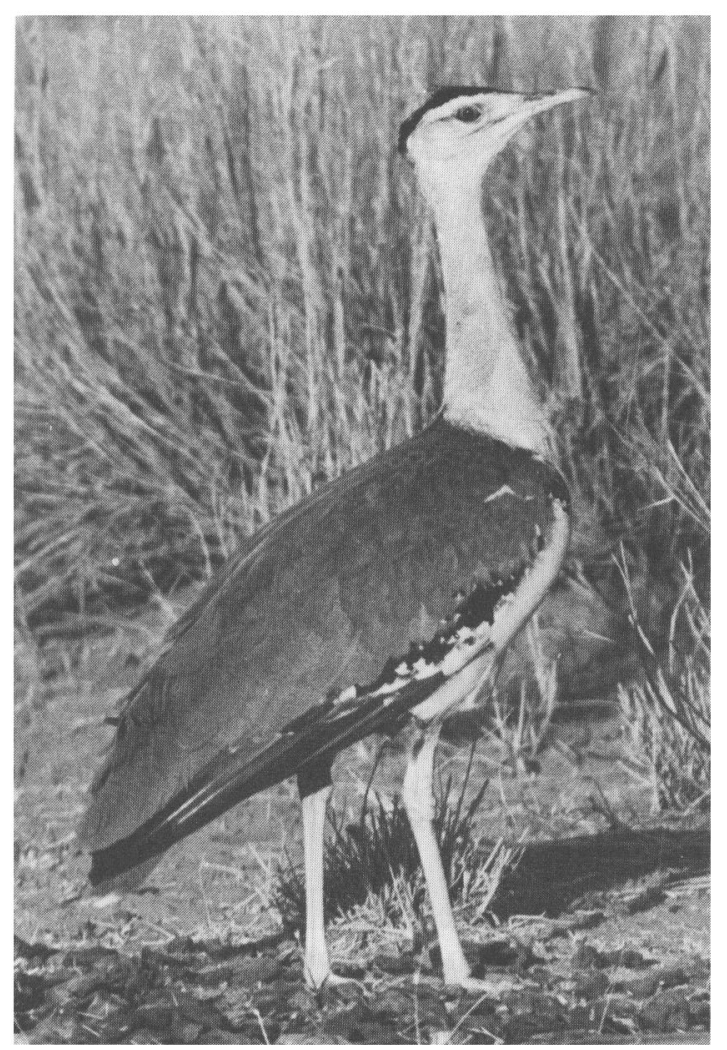

A female great Indian bustard (Asad Rahmani/ Bombay Natural History Society).

1986). As the breeding season approaches, adult males separate to establish territories. It is possible that a male occupies the same territory every year; one colour-banded male occupied the same territory for three consecutive years (the studies are still going on).

The male has a fantastic courtship display. Each morning and evening during the breeding season it stands at its favourite display spot, head up and neck fully extended. In this posture it looks around for a few minutes. Slowly, the tail is cocked and the white gular pouch is inflated. It inhales air and produces a loud 'boom', the inflated pouch possibly adding resonance to the call; on average the call is emitted every 14 seconds. Depending on the wind direction, the call can be heard for a kilometre or more.

Previous studies stated that the great Indian bustard was polygamous (Hume and Marshall, 1879; Baker, 1921; Dharmakumarsinhji, 1957, Great Indian bustard
1962; Ali and Ripley, 1969), each male collecting four or five hens in a harem. Our studies, however, show that the number of females in the 'harem' varies daily as the hens move from one territory to another or even leave the male territories. Moreover, there is no social bond between male and female. Based on Mock's (1983) recent classification of the avian mating system, the great Indian bustard is promiscuous and not polygamous.

Incubation and rearing of the chick are undertaken solely by the female. As only one egg is laid, it is not easy to discover the date of laying because it is unlikely that the egg is found on the day it is laid. However, on three occasions, we have noted hens incubating for 27 days. The chick is fed mainly with animal matter, such as insects and small lizards. Although the chick can feed itself and can leave the nest soon after it

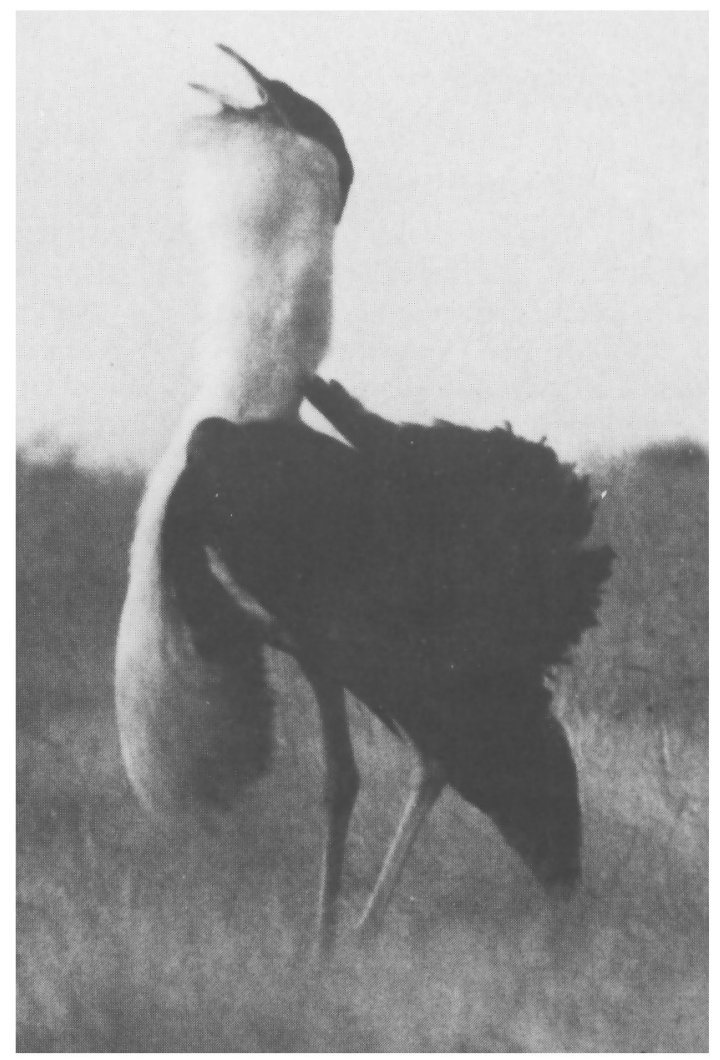

A male great Indian bustard calling while in courtship display (Asad Rahmani/Bombay Natural History Society) 




Bustard habitat in the Banni grassland in Kutch, Gujarat (Asad Rahmani/Bombay Natural History Society).

hatches, it is fed beak-to-beak for two to three months. Occasional beak-to-beak feeding is seen even when the juvenile is almost the size of the mother. The breeding season varies over the bird's range, but everywhere coincides with the period when insect populations are high. The fledgling period lasts five to six weeks, but the chick follows its mother for a year until the next breeding season.

The bird is omnivorous, and an opportunistic feeder, which help it survive in a harsh environment. The diet varies from grasshoppers, beetles, snakes and lizards to mustard, bengal gram Zizyphus sp. and wheat. The bird wanders long distances in search of food, but if the food supply is regular it becomes resident.

\section{Conservation}

The greatest problem for the conservation of the species is the protection of its habitat, i.e. grasslands and open scrub. The increase in the human population of India has pushed agriculture to marginal lands and there has been a concomitant increase in the population of livestock. For 178 example, data from the National Commission on Agriculture show that between 1951 and 1971, the cattle population increased from 155 million to 180 million and the goat population increased from 47 million to 75 million. India, with just one-fortieth of the world's total land area, supports more than half of its buffaloes, 15 per cent of its cattle, 15 per cent of its goats and 4 per cent of its sheep (Agarwal and Narain, 1985). With such a huge population of livestock, grazing pressure on the grasslands is tremendous and most of the 13-million hectares of classified grazing land are degraded to some degree.

Since the bustard nests on the ground and lays only one egg (rarely two) per clutch, the main danger to the egg is from herds of hungry cows. Even if the egg is not trampled, frequent disturbance increases the chances of egg predation or death of the embryo from over-exposure to the sun.

We found that the bird lives in a variety of habitats: sandy deserts (e.g. western Rajasthan), open scrub (e.g. Madhya Pradesh), grasslands (e.g. Andhra Pradesh, Maharashtra) and Oryx Vol 21 No 3, July 1987 
marginal fields (eastern Rajasthan, certain parts of Madhya Pradesh). Nevertheless, wherever it is found it prefers open areas with a minimum of tree cover, and the height of ground vegetation to be below its eye level. Observations at our field station in Maharashtra revealed that the ideal habitat for the great Indian bustard is a wide undulating plain with grass cover $30-70 \mathrm{~cm}$ high and an occasional bush or shrub. Total protection of the habitat in some of the newly established bustard sanctuaries allowed the vegetation to grow too high, so that within two or three years the habitat became unsuitable for bustards. Vegetation was then therefore either cut, as in Ghatigaon, or grazed, as in Karera. In the Desert National Park in Rajasthan, enclosures of 5001000 ha were established for bustards to breed undisturbed. For the first one or two years, while the vegetation was recovering, bustards were seen there, but now, after five years of total protection, bustards are seldom seen inside the enclosures. We have suggested to the Government that the grass should be either cut or grazed for a few months each year.

One of the major problems of bustard conservation is that the bird lives in grasslands and lightly grazed areas and not in forests where most of the Indian wildlife sanctuaries and national parks are located. Bustard areas are used intensively by human beings and so it is impossible to establish sanctuaries of 200-500 sq km that are free of human disturbance. Most of the bustard sanctuaries/closed areas listed in Table 1 consist of crop fields, villages and common grazing lands. In a few cases the forest department responsible for protecting the bird does not own any land in these areas. The bird is totally protected, but not its home. As it is neither possible nor desirable to evict people, nor to control grazing in the traditional grazing areas, we have suggested to the Indian Government that 100-200 ha pasture plots should be established in the bustard sanctuaries. In most of the areas the bustard breeds during the monsoon-the time when grazing inside the plots should be banned to allow the grass to grow. Once the monsoon is over, the plots should be opened to the villagers for limited grazing or grass cutting. In this way the local people will benefit from bustard conservation. In Maharashtra State many of the large pasture plots (more than 50-ha) established within the last 10 years under the Drought-Prone Areas Programme now serve as good breeding ground for the great Indian bustard. Bustard conservation should go hand-in-hand with the ecodevelopment of the much-abused semi-arid and arid regions of India.

\section{Acknowledgments}

This study was made possible with funds provided by US Fish and Wildife Service, Grant No. 8851-653-04 via the Government of India. I am grateful to Dr Sálim Ali, Mr J. C. Daniel and $\mathrm{Mr} \mathrm{S}$. A. Hussain of the BNHS for comments during the writing of this report. I am also thankful to my colleagues Mr Ranjit Manakadan and Mr Bharat Bhushan who assisted in the field work, and to Mr Carl D'Silva for the artwork. On behalf of the BNHS, I want to express my gratitude to the forest departments of the following state governments for providing full facilities to us during the study period: Maharashtra, Madhya Pradesh, Karnataka, Andhra Pradesh, Rajasthan and Gujarat.

\section{References}

Agarwal, A. and Narain, S. 1985. The State of India's Environment 1984-85. The Second Citizen's Report. Centre for Science and Environment, New Delhi, India.

Ali, S. 1970. The Great Indian Bustard Choriotis nigriceps (Vigors). IUCN Eleventh Technical Meeting, Vol. Il, No. 18 , pp. $58-62,1969$

Ali, S. and Ripley, S.D. 1969. Handbook of the Birds of India and Pakistan. Vol. 2, pp. 188-201. Oxford University Press, Dehli.

Baker, E.C.S. 1921. The Game Birds of India, Burma and Ceylon. Vol. II, pp. 165-185. John Bale Sons \& Danielsson Ltd, Oxford House, London.

Dharmakumarsinhij, R.S. 1957. Ecological Study of the Great Indian Bustard Ardeotis nigriceps (Vigors) (Aves: Otididae) Kathiawar Peninsula, Western India. J. Zool. Soc. India, 9, 140-152.

Dharmakumarsinhij, R.S. 1962. Display, Posturing and behaviour of the great Indian bustard Choriotis nigriceps (Vigors). Proceeding 2nd All-India Congress of Zoology. 2, 277-283

Goriup, P.D. and Vardhan. H. (Eds) 1983. Bustards in Decline. Tourism and Wildlife Society of India, Jaipur. India.

Hume, A.O. and Marshall, C.H.T. 1979. Game Birds of India, Burmah and Ceylon. Vol. I, pp. 1-33. 8 Hastings Street, Calcutta, India

Mock, D.W. 1983. On the study of avian mating systems. In Perspective in Omithology (Eds A. H. Bush and G. H. Clark), pp. 55-84. Cambridge University Press, London.

Rahmani, A.R and Manakadan, R. 1986. Movement and flock composition of the great Indian bustard Ardeotis nigriceps (Vigors) at Nanaj, Solapur district, Maharashtra, India. J. Bombay Natural Hist. Soc. 83, 17-31.

Asad R. Rahmani, Bombay Natural History Society, Hombill House, Shahid Bhagat Singh Road, Bombay 400 023, India. 